\title{
Fixed point theorems for Ćirić type mapping and application to integral equation
}

Jeong Sheok Ume*

\section{*Correspondence:}

jsume@changwon.ac.kr

Department of Mathematics,

Changwon National University,

Changwon, 641-773, Korea

\section{Springer}

\begin{abstract}
In this paper, we introduce a new class of Ćirić type single-valued mapping with respect to $u$-distance and prove some fixed point theorems for this mapping. An example is given to show that our results are a proper extension of many well-known results. As an application, we establish the existence of a solution for an integral equation.
\end{abstract}

\section{Introduction}

The Banach contraction principle is a remarkable result in metric fixed point theory. Over the years, it has been generalized in different directions and spaces by several mathematicians, see [1-17] and the references therein. In 1974, Ćirić [5] proved the following fixed point theorem on a complete metric space, which generalizes the Banach contraction principle: Let $X$ be a complete metric space and let $T: X \rightarrow X$ be a quasi-contractive mapping; i.e., there exists a constant $q \in[0,1)$ such that, for all $x, y \in X$,

$$
d(T x, T y) \leq q \cdot \max \{d(x, y), d(x, T x), d(y, T y), d(x, T y), d(y, T x)\} .
$$

Then:

(1) $T$ has a unique fixed point $w$ in $X$.

(2) $\lim _{n \rightarrow \infty} T^{n} x=w$ for every $x \in X$.

(3) $d\left(T^{n} x, w\right) \leq\left[\frac{q^{n}}{1-q}\right] d(x, T x)$ for every $x$ in $X$.

Recently, Ume [15] generalized the notion of $\tau$-distance [18] by introducing $u$-distance as follows.

Let $X$ be metric space with metric $d$. Then a function $p: X \times X \rightarrow R_{+}$is called a $u$ distance on $X$ if there exists a function $\theta: X \times X \times R_{+} \times R_{+} \rightarrow R_{+}$such that the following hold for $x, y, z \in X$ :

$\left(\mathrm{u}_{1}\right) p(x, z) \leq p(x, y)+p(y, z)$

$\left(\mathrm{u}_{2}\right) \theta(x, y, 0,0)=0$ and $\theta(x, y, s, t) \geq \min \{s, t\}$ for each $s, t \in R_{+}$, and for any $x \in X$ and for every $\varepsilon>0$, there exists $\delta>0$ such that $\left|s-s_{0}\right|<\delta,\left|t-t_{0}\right|<\delta, s, s_{0}, t, t_{0} \in R_{+}$and $y \in X$ imply $\left|\theta(x, y, s, t)-\theta\left(x, y, s_{0}, t_{0}\right)\right|<\varepsilon$;

$\left(\mathrm{u}_{3}\right) \lim _{n \rightarrow \infty} x_{n}=x$ and $\lim _{n \rightarrow \infty} \sup \left\{\theta\left(w_{n}, z_{n}, p\left(w_{n}, x_{m}\right), p\left(z_{n}, x_{m}\right)\right): m \geq n\right\}=0$ imply $p(y, x) \leq \lim _{n \rightarrow \infty} \inf p\left(y, x_{n}\right)$ for all $y \in X$;

$\left(\mathrm{u}_{4}\right) \lim _{n \rightarrow \infty} \sup \left\{p\left(x_{n}, w_{m}\right): m \geq n\right\}=0, \lim _{n \rightarrow \infty} \sup \left\{p\left(y_{n}, z_{m}\right): m \geq n\right\}=0, \lim _{n \rightarrow \infty} \theta\left(x_{n}\right.$, $\left.w_{n}, s_{n}, t_{n}\right)=0, \lim _{n \rightarrow \infty} \theta\left(y_{n}, z_{n}, s_{n}, t_{n}\right)=0$ imply $\lim _{n \rightarrow \infty} \theta\left(w_{n}, z_{n}, s_{n}, t_{n}\right)=0$ or 
$\lim _{n \rightarrow \infty} \sup \left\{p\left(w_{m}, x_{n}\right): m \geq n\right\}=0, \lim _{n \rightarrow \infty} \sup \left\{p\left(z_{m}, y_{n}\right): m \geq n\right\}=0, \lim _{n \rightarrow \infty} \theta\left(x_{n}\right.$, $\left.w_{n}, s_{n}, t_{n}\right)=0, \lim _{n \rightarrow \infty} \theta\left(y_{n}, z_{n}, s_{n}, t_{n}\right)=0$ imply $\lim _{n \rightarrow \infty} \theta\left(w_{n}, z_{n}, s_{n}, t_{n}\right)=0 ;$

$\left(\mathrm{u}_{5}\right) \lim _{n \rightarrow \infty} \theta\left(w_{n}, z_{n}, p\left(w_{n}, x_{n}\right), p\left(z_{n}, x_{n}\right)\right)=0, \lim _{n \rightarrow \infty} \theta\left(w_{n}, z_{n}, p\left(w_{n}, y_{n}\right), p\left(z_{n}, y_{n}\right)\right)=0$ imply $\lim _{n \rightarrow \infty} d\left(x_{n}, y_{n}\right)=0$ or $\lim _{n \rightarrow \infty} \theta\left(a_{n}, b_{n}, p\left(x_{n}, a_{n}\right), p\left(x_{n}, b_{n}\right)\right)=0, \lim _{n \rightarrow \infty} \theta\left(a_{n}, b_{n}\right.$, $\left.p\left(y_{n}, a_{n}\right), p\left(y_{n}, b_{n}\right)\right)=0$ imply $\lim _{n \rightarrow \infty} d\left(x_{n}, y_{n}\right)=0$.

\section{Remark $1.1([15])$}

(a) Suppose that $\theta$ from $X \times X \times R_{+} \times R_{+}$into $R_{+}$is a mapping satisfying $\left(\mathrm{u}_{2}\right) \sim\left(\mathrm{u}_{5}\right)$. Then there exists a mapping $\eta$ from $X \times X \times R_{+} \times R_{+}$into $R_{+}$such that $\eta$ is nondecreasing in its third and fourth variable, satisfying $\left(\mathrm{u}_{2}\right)_{\eta} \sim\left(\mathrm{u}_{5}\right)_{\eta}$, where $\left(\mathbf{u}_{2}\right)_{\eta} \sim\left(\mathbf{u}_{5}\right)_{\eta}$ stand for substituting $\eta$ for $\theta$ in $\left(\mathbf{u}_{2}\right) \sim\left(\mathbf{u}_{5}\right)$, respectively.

(b) On account of (a), we may assume that $\theta$ is nondecreasing in its third and fourth variables, respectively, for a function $\theta$ from $X \times X \times R_{+} \times R_{+}$into $R_{+}$satisfying $\left(\mathrm{u}_{2}\right) \sim\left(\mathrm{u}_{5}\right)$.

(c) Each $\tau$-distance $p$ on a metric space $(X, d)$ is also a $u$-distance on $X$. We present some example of $u$-distance which are not $\tau$-distance. (For details, see [15].)

Example 1.2 Let $X=R_{+}$with the usual metric. Define $p: X \times X \rightarrow R_{+}$by $p(x, y)=\left(\frac{1}{4}\right) x^{2}$. Then $p$ is a $u$-distance on $\mathrm{X}$ but not a $\tau$-distance on $X$.

Example 1.3 Let $X$ be a normed space with norm $\|\cdot\|$. Then a function $p: X \times X \rightarrow R_{+}$ defined by $p(x, y)=\|x\|$ for every $x, y \in X$ is a $u$-distance on $X$ but not a $\tau$-distance.

It follows from the above example and Remark 1.1(c) that $u$-distance is a proper extension of $\tau$-distance. Other useful examples on $u$-distance are given in [15].

\section{Preliminaries}

Throughout this paper we denote by $N$ the set of all positive integers, by $R$ the set of all real numbers and by $R_{+}$the set of all nonnegative real numbers.

Definition 2.1 ([15]) Let $X$ be a metric space with a metric $d$ and let $p$ be a $u$-distance on $X$. Then a sequence $\left\{x_{n}\right\}$ in $\mathrm{X}$ is called $p$-Cauchy if there exists a function $\theta$ from $X \times$ $X \times R_{+} \times R_{+}$into $R_{+}$satisfying $\left(\mathrm{u}_{2}\right) \sim\left(\mathrm{u}_{5}\right)$ and a sequence $\left\{z_{n}\right\}$ of $X$ such that

$$
\begin{aligned}
& \lim _{n \rightarrow \infty} \sup \left\{\theta\left(z_{n}, z_{n}, p\left(z_{n}, x_{m}\right), p\left(z_{n}, x_{m}\right)\right): m \geq n\right\}=0 \quad \text { or } \\
& \lim _{n \rightarrow \infty} \sup \left\{\theta\left(z_{n}, z_{n}, p\left(x_{m}, z_{n}\right), p\left(x_{m}, z_{n}\right)\right): m \geq n\right\}=0 .
\end{aligned}
$$

Lemma $2.2([15])$ Let $X$ be a metric space with a metric $d$ and let $p$ a $u$-distance on $X$. If $\left\{x_{n}\right\}$ is a p-Cauchy sequence, then $\left\{x_{n}\right\}$ is a Cauchy sequence.

Lemma 2.3 ([15]) Let $X$ be a metric space with a metric $d$ and let $p$ be a $u$-distance on $X$.

(1) If sequences $\left\{x_{n}\right\}$ and $\left\{y_{n}\right\}$ of $X$ satisfy $\lim _{n \rightarrow \infty} p\left(z, x_{n}\right)=0$ and $\lim _{n \rightarrow \infty} p\left(z, y_{n}\right)=0$ for some $z \in X$, then $\lim _{n \rightarrow \infty} d\left(x_{n}, y_{n}\right)=0$.

(2) If $p(z, x)=0$ and $p(z, y)=0$, then $x=y$.

(3) Suppose that sequences $\left\{x_{n}\right\}$ and $\left\{y_{n}\right\}$ of $X$ satisfy $\lim _{n \rightarrow \infty} p\left(x_{n}, z\right)=0$ and $\lim _{n \rightarrow \infty} p\left(y_{n}, z\right)=0$ for some $z \in X$, then $\lim _{n \rightarrow \infty} d\left(x_{n}, y_{n}\right)=0$.

(4) If $p(x, z)=0$ and $p(y, z)=0$, then $x=y$. 
Lemma 2.4 ([15]) Let $X$ be a metric space with a metric $d$ and let $p$ be a $u$-distance on $X$. Suppose that a sequence $\left\{x_{n}\right\}$ of $X$ satisfies

$$
\begin{aligned}
& \lim _{n \rightarrow \infty} \sup \left\{p\left(x_{n}, x_{m}\right): m \geq n\right\}=0 \quad \text { or } \\
& \lim _{n \rightarrow \infty} \sup \left\{p\left(x_{m}, x_{n}\right): m \geq n\right\}=0 .
\end{aligned}
$$

Then:

(i) $\left\{x_{n}\right\}$ is a p-Cauchy sequence.

(ii) If $\left\{x_{n}\right\}$ is a $p$-Cauchy sequence, then $\left\{x_{n}\right\}$ is a Cauchy sequence.

\section{Fixed point theorems}

The following lemma plays an important role in proving our theorems.

Lemma 3.1 Let $(X, d)$ be a metric space with a $u$-distance $p$ on $X$ and $\left\{a_{n}\right\}$ and $\left\{b_{n}\right\}$ be sequences of $X$ such that

$$
\begin{aligned}
& \lim _{n \rightarrow \infty} \sup \left\{p\left(a_{n}, a_{m}\right): m>n\right\}=0 \quad \text { and } \\
& \lim _{n \rightarrow \infty} \sup \left\{p\left(a_{n}, b_{m}\right): m>n\right\}=0 .
\end{aligned}
$$

Then there exist a subsequence $\left\{a_{k_{n}}\right\}$ of $\left\{a_{n}\right\}$ and a subsequence $\left\{b_{k_{n}}\right\}$ of $\left\{b_{n}\right\}$ such that $\lim _{n \rightarrow \infty} d\left(a_{k_{n}}, b_{k_{n}}\right)=0$.

Proof Since $p$ is a $u$-distance on $X$,

there exists a mapping $\theta: X \times X \times R_{+} \times R_{+} \rightarrow R_{+}$

such that $\theta$ is nondecreasing in its third and

fourth variable respectively, satisfying $\left(\mathrm{u}_{2}\right) \sim\left(\mathrm{u}_{5}\right)$.

For each $n \in N$, let

$$
\alpha_{n}=\sup \left\{p\left(a_{n}, a_{m}\right): m>n\right\} \quad \text { and } \quad \beta_{n}=\sup \left\{p\left(a_{n}, b_{m}\right): m>n\right\} .
$$

By the hypotheses and (3.2), we have

$$
\lim _{n \rightarrow \infty}\left(\alpha_{n}+\beta_{n}\right)=0
$$

Let $k_{1} \in N$ be an arbitrary and fixed element. Then, by $\left(\mathrm{u}_{2}\right)$, for this $a_{k_{1}} \in X$ and $\varepsilon=1$, there exists $\delta_{1}>0$ such that

$$
|s|=s<\delta_{1}, \quad|t|=t<\delta_{1}, \quad y \in X \quad \text { imply } \quad \theta\left(a_{k_{1}}, y, s, t\right)<1 .
$$

By virtue of (3.3) and (3.4), for this $\delta_{1}>0$, there exists $M_{1} \in N$ such that

$$
n \geq M_{1} \text { implies } \quad \alpha_{n}+\beta_{n}<\delta_{1} .
$$


Let $k_{2} \in N$ be such that

$$
k_{2} \geq \max \left\{1+k_{1}, M_{1}\right\} .
$$

Due to (3.6), we have

$$
k_{1}<k_{2} \quad \text { and } \quad k_{2} \geq M_{1} \text {. }
$$

From (3.4), (3.5), (3.6), and (3.7) we get

$$
\theta\left(a_{k_{1}}, a_{k_{2}}, \alpha_{k_{2}}+\beta_{k_{2}}, \alpha_{k_{2}}+\beta_{k_{2}}\right)<1
$$

In terms of $\left(\mathrm{u}_{2}\right)$ and (3.6), for this $a_{k_{2}} \in X$ and $\varepsilon=\frac{1}{2}$, there exists $\delta_{2}>0$ such that $|s|=s<\delta_{2}$, $|t|=t<\delta_{2}, y \in X$ imply

$$
\theta\left(a_{k_{2}}, y, s, t\right)<\frac{1}{2}
$$

In view of (3.3) and (3.9), for this $\delta_{2}>0$, there exists $M_{2} \in N$ such that

$$
n \geq M_{2} \quad \text { implies } \quad \alpha_{n}+\beta_{n}<\delta_{2} .
$$

Let $k_{3} \in N$ be such that

$$
k_{3} \geq \max \left\{1+k_{2}, M_{2}\right\} .
$$

On account of (3.9), (3.10), (3.11), we obtain

$$
k_{2}<k_{3} \text { and } \theta\left(a_{k_{2}}, a_{k_{3}}, \alpha_{k_{3}}+\beta_{k_{3}}, \alpha_{k_{3}}+\beta_{k_{3}}\right)<\frac{1}{2} \text {. }
$$

Continuing this process, there exist a subsequence $\left\{a_{k_{n}}\right\}$ of $\left\{a_{n}\right\}$, and a subsequence $\left\{b_{k_{n}}\right\}$ of $\left\{b_{n}\right\}$ such that, for all $n \in N$,

$$
\theta\left(a_{k_{n}}, a_{k_{n+1}}, \alpha_{k_{n+1}}+\beta_{k_{n+1}}, \alpha_{k_{n+1}}+\beta_{k_{n+1}}\right)<\frac{1}{n} .
$$

Using (3.2), (3.3), and (3.13), we know that

$$
\begin{aligned}
& \lim _{n \rightarrow \infty}\left\{\sup \left[p\left(a_{k_{n}}, a_{k_{m+1}}\right): m \geq n\right]\right\} \\
& \quad \leq \lim _{n \rightarrow \infty}\left\{\sup \left[p\left(a_{k_{n}}, a_{l}\right): l>k_{n}\right]\right\} \\
& \quad=\lim _{n \rightarrow \infty} \alpha_{k_{n}}=0 \text { and } \\
& \lim _{n \rightarrow \infty} \theta\left(a_{k_{n}}, a_{k_{n+1}}, \alpha_{k_{n+1}}+\beta_{k_{n+1}}, \alpha_{k_{n+1}}+\beta_{k_{n+1}}\right)=0 .
\end{aligned}
$$

Using (3.1), (3.2), (3.14) and putting $x_{n}=y_{n}=a_{k_{n}}, w_{m}=z_{m}=a_{k_{m+1}}$ and $s_{n}=t_{n}=\alpha_{k_{n+1}}+\beta_{k_{n+1}}$ in $\left(\mathrm{u}_{4}\right)$ we deduce

$$
\begin{aligned}
& \lim _{n \rightarrow \infty} \theta\left(a_{k_{n+1}}, a_{k_{n+1}}, p\left(a_{k_{n+1}}, a_{k_{n+2}}\right), p\left(a_{k_{n+1}}, a_{k_{n+2}}\right)\right)=0 \quad \text { and } \\
& \lim _{n \rightarrow \infty} \theta\left(a_{k_{n+1}}, a_{k_{n+1}}, p\left(a_{k_{n+1}}, b_{k_{n+2}}\right), p\left(a_{k_{n+1}}, b_{k_{n+2}}\right)\right)=0 .
\end{aligned}
$$


Using (3.15) and putting $w_{n}=z_{n}=a_{k_{n+1}}, x_{n}=a_{k_{n+2}}$, and $y_{n}=b_{k_{n+2}}$ in $\left(\mathrm{u}_{5}\right)$, we have

$$
\lim _{n \rightarrow \infty} d\left(a_{k_{n+2}}, b_{k_{n+2}}\right)=0
$$

Due to (3.13) and (3.16), there exist a subsequence $\left\{a_{k_{n}}\right\}$ of $\left\{a_{n}\right\}$ and a subsequence $\left\{b_{k_{n}}\right\}$ of $\left\{b_{n}\right\}$ such that

$$
\lim _{n \rightarrow \infty} d\left(a_{k_{n}}, b_{k_{n}}\right)=0
$$

Definition 3.2 Let $(X, d)$ be a metric space with a $u$-distance $p$ on $X$ and let $T$ be a selfmapping on $X$. For $A \subseteq X$, let $\delta(A)=\sup \{p(x, y): x, y \in A\}$ and for each $x, y \in X, n \in N$, let

$$
O(x, y, n)=\left\{T^{i} x, T^{j} y: 0 \leq i, j \leq n, i, j \in N \cup\{0\}\right\}
$$

where $T^{0} x=x$ and $T^{i}$ is the $i$ times repeated composition of $T$ with itself. Let

$$
O(x, y, \infty)=\left\{T^{i} x, T^{j} y: i, j \in N \cup\{0\}\right\}
$$

for each $x, y \in X$.

Lemma 3.3 Let $(X, d)$ be a metric space with a $u$-distance $p$ on $X$. Let $T: X \rightarrow X$ and $\varphi: R_{+} \rightarrow R_{+}$be mappings that satisfy the following conditions:

(i) $p(T x, T y) \leq \varphi(\max \{p(x, y), p(x, T x), p(y, T y), p(x, T y), p(y, T x)$,

$$
p(y, x), p(T x, x), p(T y, y), p(T y, x), p(T x, y)\})
$$

for all $x, y \in X$

(ii) $\varphi$ is nondecreasing and $\varphi(t)<t$ for all $t>0$;

(iii) $I-\varphi$ is nondecreasing and bijective, where $I$ is identity mapping on $R_{+}$;

(iv) $\sum_{n=1}^{\infty} \varphi^{n}(t)<\infty \quad$ for each $t \in(0, \infty)$,

where $\varphi^{n}$ is n-times repeated composition of $\varphi$ with itself.

Then:

(1) For each $x, y \in X$ and $n \in N$,

$$
\begin{aligned}
& \max \left\{p\left(T^{i} x, T^{j} x\right), p\left(T^{i} x, T^{j} y\right), p\left(T^{i} y, T^{j} x\right), p\left(T^{i} y, T^{j} y\right) \mid i, j \in N, i, j \leq n\right\} \\
& \quad \leq \varphi(\delta(O(x, y, n))) .
\end{aligned}
$$

(2) For each $x, y \in X, n \in N$ and for each $i \in N$ with $i \leq 8$, there exists $l_{i} \in N$ with $l_{i} \leq n$ such that

$$
\begin{aligned}
\delta(O(x, y, n))= & \max \left\{p(x, x), p(x, y), p(y, x), p(y, y), p\left(x, T^{l_{1}} x\right), p\left(x, T^{l_{2}} y\right),\right. \\
& \left.p\left(y, T^{l_{3}} x\right), p\left(y, T^{l_{4}} y\right), p\left(T^{l_{5}} x, x\right), p\left(T^{l_{6}} x, y\right), p\left(T^{l_{7}} y, x\right), p\left(T^{l_{8}} y, y\right)\right\} .
\end{aligned}
$$


(3) For each $x, y \in X$,

$$
\delta(O(x, y, \infty)) \leq(I-\varphi)^{-1}(b(x, y))
$$

where $b(x, y)=p(x, x)+p(y, y)+p(x, y)+p(y, x)+p(x, T x)+p(T x, x)+p(y, T y)+$ $p(T y, y)$.

(4) For each $x \in X,\left\{T^{n} x\right\}$ is a Cauchy sequence.

(5) For each $x, y \in X$ and $n \in N$,

$$
p\left(T^{n} x, T^{n} y\right) \leq \varphi^{n-1}\left((I-\varphi)^{-1}(b(x, y))\right)
$$

(6) For each $x, y \in X, \lim _{n \rightarrow \infty} p\left(T^{n} x, T^{n} y\right)=0$.

Proof Let $x, y \in X$ and $n \in N$, and let $i$ and $j$ be natural numbers with $i, j \leq n$. Then $T^{i-1} x, T^{i} x, T^{j-1} x, T^{j} x, T^{i-1} y, T^{i} y, T^{j-1} y, T^{j} y \in O(x, y, n)$.

From (3.18) and hypothesis (ii), we have

$$
\begin{aligned}
& p\left(T^{i} x, T^{j} x\right)=p\left(T T^{i-1} x, T T^{j-1} x\right) \\
& \leq \varphi\left(\operatorname { m a x } \left\{p\left(T^{i-1} x, T^{j-1} x\right), p\left(T^{i-1} x, T^{i} x\right), p\left(T^{j-1} x, T^{j} x\right), p\left(T^{i-1} x, T^{j} x\right),\right.\right. \\
& p\left(T^{j-1} x, T^{i} x\right), p\left(T^{j-1} x, T^{i-1} x\right), p\left(T^{i} x, T^{i-1} x\right), \\
& \left.\left.p\left(T^{j} x, T^{j-1} x\right), p\left(T^{j} x, T^{i-1} x\right), p\left(T^{i} x, T^{j-1} x\right)\right\}\right) \\
& \leq \varphi(\delta(O(x, y, n))) \\
& p\left(T^{i} x, T^{j} y\right)=p\left(T T^{i-1} x, T T^{j-1} y\right) \\
& \leq \varphi\left(\operatorname { m a x } \left\{p\left(T^{i-1} x, T^{j-1} y\right), p\left(T^{i-1} x, T^{i} x\right), p\left(T^{j-1} y, T^{j} y\right), p\left(T^{i-1} x, T^{j} y\right),\right.\right. \\
& p\left(T^{j-1} y, T^{i} x\right), p\left(T^{j-1} y, T^{i-1} x\right), p\left(T^{i} x, T^{i-1} x\right), \\
& \left.\left.p\left(T^{j} y, T^{j-1} y\right), p\left(T^{j} y, T^{i-1} x\right), p\left(T^{i} x, T^{j-1} y\right)\right\}\right) \\
& \leq \varphi(\delta(O(x, y, n))) \\
& p\left(T^{i} y, T^{j} x\right)=p\left(T T^{i-1} y, T T^{j-1} x\right) \\
& \leq \varphi\left(\operatorname { m a x } \left\{p\left(T^{i-1} y, T^{j-1} x\right), p\left(T^{i-1} y, T^{i} y\right), p\left(T^{j-1} x, T^{j} x\right), p\left(T^{i-1} y, T^{j} x\right),\right.\right. \\
& p\left(T^{j-1} x, T^{i} y\right), p\left(T^{j-1} x, T^{i-1} y\right), p\left(T^{i} y, T^{i-1} y\right), \\
& \left.\left.p\left(T^{j} x, T^{j-1} x\right), p\left(T^{j} x, T^{i-1} y\right), p\left(T^{i} y, T^{j-1} x\right)\right\}\right) \\
& \leq \varphi(\delta(O(x, y, n))) \\
& p\left(T^{i} y, T^{j} y\right)=p\left(T T^{i-1} y, T T^{j-1} y\right) \\
& \leq \varphi\left(\operatorname { m a x } \left\{p\left(T^{i-1} y, T^{j-1} y\right), p\left(T^{i-1} y, T^{i} y\right), p\left(T^{j-1} y, T^{j} y\right), p\left(T^{i-1} y, T^{j} y\right),\right.\right. \\
& p\left(T^{j-1} y, T^{i} y\right), p\left(T^{j-1} y, T^{i-1} y\right), p\left(T^{i} y, T^{i-1} y\right), \\
& \left.\left.p\left(T^{j} y, T^{j-1} y\right), p\left(T^{j} y, T^{i-1} y\right), p\left(T^{i} y, T^{j-1} y\right)\right\}\right) \\
& \leq \varphi(\delta(O(x, y, n)))
\end{aligned}
$$

which proves (1). 
From (1), it follows that for each $x, y \in X, n \in N$ and for each $i \in N$ with $i \leq 8$, there exists $l_{i} \in N$ with $l_{i} \leq n$ such that

$$
\begin{aligned}
\delta(O(x, y, n))= & \max \left\{p(x, x), p(x, y), p(y, x), p(y, y), p\left(x, T^{l_{1}} x\right), p\left(x, T^{l_{2}} y\right), p\left(y, T^{l_{3}} x\right),\right. \\
& \left.p\left(y, T^{l_{4}} y\right), p\left(T^{l_{5}} x, x\right), p\left(T^{l_{6}} x, y\right), p\left(T^{l_{7}} y, x\right), p\left(T^{l_{8}} y, y\right)\right\},
\end{aligned}
$$

which proves (2).

Applying the triangle inequality, hypothesis (iii), (1), and (2), we have

$$
\begin{aligned}
& p\left(x, T^{l_{1}} x\right) \leq p(x, T x)+p\left(T x, T^{l_{1}} x\right) \leq p(x, T x)+\varphi(\delta(O(x, y, n))), \\
& p\left(x, T^{l_{2}} y\right) \leq p(x, T x)+p\left(T x, T^{l_{2}} y\right) \leq p(x, T x)+\varphi(\delta(O(x, y, n))), \\
& p\left(y, T^{l_{3}} x\right) \leq p(y, T y)+p\left(T y, T^{l_{3}} x\right) \leq p(y, T y)+\varphi(\delta(O(x, y, n))), \\
& p\left(y, T^{l_{4}} x\right) \leq p(y, T y)+p\left(T y, T^{l_{4}} x\right) \leq p(y, T y)+\varphi(\delta(O(x, y, n))), \\
& p\left(T^{l_{5}} x, x\right) \leq p\left(T^{l_{5}} x, T x\right)+p(T x, x) \leq p(T x, x)+\varphi(\delta(O(x, y, n))), \\
& p\left(T^{l_{6}} x, y\right) \leq p\left(T^{l_{6}} x, T y\right)+p(T y, y) \leq p(T y, y)+\varphi(\delta(O(x, y, n))), \\
& p\left(T^{l_{7}} y, x\right) \leq p\left(T^{l_{7}} y, T x\right)+p(T x, x) \leq p(T x, x)+\varphi(\delta(O(x, y, n))), \\
& p\left(T^{l_{8}} y, y\right) \leq p\left(T^{l_{8}} y, T y\right)+p(T y, y) \leq p(T y, y)+\varphi(\delta(O(x, y, n))) .
\end{aligned}
$$

Therefore $\delta(O(x, y, n)) \leq(I-\varphi)^{-1}(b(x, y))$.

Since $n$ is arbitrary, the proof of (3) is complete.

To prove (4), let $x$ be an arbitrary point of $X$ and define $x_{n}=T^{n} x$ for every $n \in N$. On account of (3.18) and hypothesis (ii), we have

$$
\begin{aligned}
p\left(x_{n}, x_{n+1}\right)= & p\left(T x_{n-1}, T x_{n}\right) \\
\leq & \varphi\left(\operatorname { m a x } \left\{p\left(x_{n-1}, x_{n}\right), p\left(x_{n-1}, x_{n}\right), p\left(x_{n}, x_{n+1}\right), p\left(x_{n-1}, x_{n+1}\right), p\left(x_{n}, x_{n}\right),\right.\right. \\
& \left.\left.p\left(x_{n}, x_{n-1}\right), p\left(x_{n}, x_{n-1}\right), p\left(x_{n+1}, x_{n}\right), p\left(x_{n+1}, x_{n-1}\right), p\left(x_{n}, x_{n}\right)\right\}\right), \\
p\left(x_{n+1}, x_{n}\right)= & p\left(T x_{n}, T x_{n-1}\right) \\
\leq & \varphi\left(\operatorname { m a x } \left\{p\left(x_{n}, x_{n-1}\right), p\left(x_{n}, x_{n+1}\right), p\left(x_{n-1}, x_{n}\right), p\left(x_{n}, x_{n}\right), p\left(x_{n-1}, x_{n+1}\right),\right.\right. \\
& \left.\left.p\left(x_{n-1}, x_{n}\right), p\left(x_{n+1}, x_{n}\right), p\left(x_{n}, x_{n-1}\right), p\left(x_{n}, x_{n}\right), p\left(x_{n+1}, x_{n-1}\right)\right\}\right), \\
p\left(x_{n-1}, x_{n}\right)= & p\left(T x_{n-2}, T x_{n-1}\right) \\
\leq & \varphi\left(\operatorname { m a x } \left\{p\left(x_{n-2}, x_{n-1}\right), p\left(x_{n-2}, x_{n-1}\right), p\left(x_{n-1}, x_{n}\right), p\left(x_{n-2}, x_{n}\right), p\left(x_{n-1}, x_{n-1}\right),\right.\right. \\
& \left.\left.p\left(x_{n-1}, x_{n-2}\right), p\left(x_{n-1}, x_{n-2}\right), p\left(x_{n}, x_{n-1}\right), p\left(x_{n}, x_{n-2}\right), p\left(x_{n-1}, x_{n-1}\right)\right\}\right) \\
p\left(x_{n}, x_{n-1}\right)= & p\left(T x_{n-1}, T x_{n-2}\right) \\
\leq & \varphi\left(\operatorname { m a x } \left\{p\left(x_{n-1}, x_{n-2}\right), p\left(x_{n-1}, x_{n}\right), p\left(x_{n-2}, x_{n-1}\right), p\left(x_{n-1}, x_{n-1}\right), p\left(x_{n-2}, x_{n}\right),\right.\right. \\
& \left.\left.p\left(x_{n-2}, x_{n-1}\right), p\left(x_{n}, x_{n-1}\right), p\left(x_{n-1}, x_{n-2}\right), p\left(x_{n-1}, x_{n-1}\right), p\left(x_{n}, x_{n-2}\right)\right\}\right), \\
p\left(x_{n-1}, x_{n+1}\right)= & p\left(T x_{n-2}, T x_{n}\right) \\
& \leq \varphi\left(\operatorname { m a x } \left\{p\left(x_{n-2}, x_{n}\right), p\left(x_{n-2}, x_{n-1}\right), p\left(x_{n}, x_{n+1}\right), p\left(x_{n-2}, x_{n+1}\right),\right.\right.
\end{aligned}
$$




$$
\begin{gathered}
p\left(x_{n}, x_{n-1}\right), p\left(x_{n}, x_{n-2}\right), p\left(x_{n-1}, x_{n-2}\right), \\
\left.\left.p\left(x_{n+1}, x_{n}\right), p\left(x_{n+1}, x_{n-2}\right), p\left(x_{n-1}, x_{n}\right)\right\}\right), \\
p\left(x_{n+1}, x_{n-1}\right)=p\left(T x_{n}, T x_{n-2}\right) \\
\leq p\left(\operatorname { m a x } \left\{p\left(x_{n}, x_{n-2}\right), p\left(x_{n}, x_{n+1}\right), p\left(x_{n-2}, x_{n-1}\right), p\left(x_{n}, x_{n-1}\right),\right.\right. \\
p\left(x_{n-2}, x_{n+1}\right), p\left(x_{n-2}, x_{n}\right), p\left(x_{n+1}, x_{n}\right), \\
\left.\left.p\left(x_{n-1}, x_{n-2}\right), p\left(x_{n-1}, x_{n}\right), p\left(x_{n+1}, x_{n-2}\right)\right\}\right), \\
p\left(x_{n}, x_{n}\right)=p\left(T x_{n-1}, T x_{n-1}\right) \\
\leq \varphi\left(\max \left\{p\left(x_{n-1}, x_{n-1}\right), p\left(x_{n-1}, x_{n}\right), p\left(x_{n}, x_{n-1}\right)\right\}\right) .
\end{gathered}
$$

Substituting (3.21) (3.26) into (3.20), proceeding in this manner and by hypotheses, (1), (2), and (3) of Lemma 3.3, we have

$$
\begin{aligned}
p\left(x_{n}, x_{n+1}\right) \leq & \varphi\left(\max \left\{p\left(x_{i}, x_{j}\right): n-1 \leq i, j \leq n+1\right\}\right) \\
\leq & \varphi^{2}\left(\max \left\{p\left(x_{i}, x_{j}\right): n-2 \leq i, j \leq n+1\right\}\right) \\
& \vdots \\
\leq & \varphi^{n-1}\left(\max \left\{p\left(x_{i}, x_{j}\right): 1 \leq i, j \leq n+1\right\}\right) \\
\leq & \varphi^{n-1}(\delta(O(x, x, \infty))) \\
\leq & \varphi^{n-1}\left((I-\varphi)^{-1}(a(x))\right),
\end{aligned}
$$

where $a(x)=4[p(x, x)+p(x, T x)+p(T x, x)]$.

If $n<m$, then, by (3.27),

$$
\begin{aligned}
p\left(x_{n}, x_{m}\right) & \leq p\left(x_{n}, x_{n+1}\right)+p\left(x_{n+1}, x_{n+2}\right)+\cdots+p\left(x_{m-1}, x_{m}\right) \\
& =\sum_{k=n}^{m-1} p\left(x_{k}, x_{k+1}\right) \\
& \leq \sum_{k=n}^{m-1} \varphi^{k-1}\left((I-\varphi)^{-1}(a(x))\right) \\
& \leq \sum_{k=n-1}^{m} \varphi^{k}\left((I-\varphi)^{-1}(a(x))\right) .
\end{aligned}
$$

Combining (3.19) and (3.28), we get

$$
\lim _{n \rightarrow \infty} \sup \left\{p\left(x_{n}, x_{m}\right): m>n\right\}=0 .
$$

By means of Lemma 2.4 and (3.29),

$\left\{x_{n}\right\}$ is a Cauchy sequence, i.e., $\left\{T^{n} x\right\}$ is a Cauchy sequence for each $x \in X$. This is the proof of (4). 
To prove (5), let $x, y \in X$ and define $x_{n}=T^{n} x$ and $y_{n}=T^{n} y$ for every $n \in N$. By the same method as in (3.18) (3.27), we get

$$
\begin{aligned}
p\left(x_{n}, y_{n}\right) \leq & \varphi\left(\max \left\{p\left(x_{i}, x_{j}\right), p\left(x_{i}, y_{j}\right), p\left(y_{i}, x_{j}\right), p\left(y_{i}, y_{j}\right) \mid n-1 \leq i, j \leq n\right\}\right) \\
\leq & \varphi^{2}\left(\max \left\{p\left(x_{i}, x_{j}\right), p\left(x_{i}, y_{j}\right), p\left(y_{i}, x_{j}\right), p\left(y_{i}, y_{j}\right) \mid n-2 \leq i, j \leq n\right\}\right) \\
& \vdots \\
\leq & \varphi^{n-1}\left(\max \left\{p\left(x_{i}, x_{j}\right), p\left(x_{i}, y_{j}\right), p\left(y_{i}, x_{j}\right), p\left(y_{i}, y_{j}\right) \mid 1 \leq i, j \leq n\right\}\right) \\
\leq & \varphi^{n-1}(\delta(O(x, y, n))) \\
\leq & \varphi^{n-1}\left((I-\varphi)^{-1}(b(x, y))\right),
\end{aligned}
$$

which proves (5).

By virtue of (3.19) and (3.30), we deduce that

$$
\lim _{n \rightarrow \infty} p\left(T^{n} x, T^{n} y\right)=0
$$

for each $x, y \in X$. This is the proof of (6).

Definition 3.4 Let $(X, d)$ be a metric space, a mapping $T: X \rightarrow X$ is called Ćirić type $\varphi$-generalized single-valued $p$-contractive if it satisfies the following:

(c1) There exist a $u$-distance $p$ on $X$ and $\varphi:[0, \infty) \rightarrow[0, \infty)$ such that

$$
\begin{gathered}
p(T x, T y) \leq \varphi(\max [p(x, y), p(x, T x), p(y, T y), p(x, T y), p(y, T x), \\
p(y, x), p(T x, x), p(T y, y), p(T y, x), p(T x, y)])
\end{gathered}
$$

for all $x, y \in X$.

(c2) For each $x \in X$ with $\lim _{n \rightarrow \infty} T^{n} x=c_{x} \in X$, there exists $y \in X$ such that $\lim _{n \rightarrow \infty} T^{n} y=T c_{x}$.

Theorem 3.5 Let $(X, d)$ be a complete metric space with a $u$-distance $p$. Let $T: X \rightarrow X$ be Ćirić type $\varphi$-generalized single-valued p-contractive satisfying (ii) (iv) of Lemma 3.3. Then:

(1) $\lim _{n \rightarrow \infty} T^{n} x=z$ for each $x \in X$.

(2) $p\left(T^{n} x, z\right) \leq \sum_{k=n-1}^{\infty} \varphi^{k}\left((I-\varphi)^{-1}(a(x))\right)$ for each $x \in X$, where $a(x)=[p(x, x)+p(x, T x)+p(T x, x)] \times 4$.

(3) $T$ has a unique fixed point $z$ in $X$ and $p(z, z)=0$.

Proof Let $x, y \in X$ and let $x_{n}=T^{n} x$ and $y_{n}=T^{n} y$ for every $n \in N$. Then, by (4) of Lemma 3.3, $\left\{x_{n}\right\}$ is a Cauchy sequence.

Since $X$ is complete, $\left\{x_{n}\right\}$ converges to some $z \in X$. This is the proof of (1). Due to (3.28), (iv) of Lemma 3.3, Lemma 2.4, Definition 2.1, and $\left(u_{3}\right)$, we have

$$
p\left(x_{n}, z\right) \leq \lim _{m \rightarrow \infty} \inf p\left(x_{n}, x_{m}\right) \leq \sum_{k=n-1}^{\infty} \varphi^{k}\left((I-\varphi)^{-1}(a(x))\right),
$$

which proves (2). 
By (1) and (c2) of Definition 3.4, there exists $y \in X$ such that

$$
\lim _{n \rightarrow \infty} T^{n} y=T z
$$

In view of (3.29) and (3.31), we get

$$
\begin{aligned}
& \lim _{n \rightarrow \infty} \sup \left\{\sup \left[p\left(T^{n} x, T^{m} y\right): m>n\right]\right\} \\
& \quad \leq \lim _{n \rightarrow \infty} \sup \left\{\sup \left[p\left(T^{n} x, T^{m} x\right)+p\left(T^{m} x, T^{m} y\right): m>n\right]\right\} \\
& \quad \leq \lim _{n \rightarrow \infty} \sup \left\{\sup \left[p\left(T^{n} x, T^{m} x\right): m>n\right]\right\}+\lim _{n \rightarrow \infty} \sup \left\{\sup \left[p\left(T^{m} x, T^{m} y\right): m>n\right]\right\} \\
& \quad=0 .
\end{aligned}
$$

Due to (3.33), we obtain

$$
\lim _{n \rightarrow \infty} \sup \left\{p\left(T^{n} x, T^{m} y\right): m>n\right\}=0 .
$$

In terms of (3.29), (3.34), and Lemma 3.1, there exist a subsequence $\left\{x_{k_{n}}\right\}$ of $\left\{x_{n}\right\}$ and a subsequence $\left\{y_{k_{n}}\right\}$ of $\left\{y_{n}\right\}$ such that

$$
\lim _{n \rightarrow \infty} d\left(x_{k_{n}}, y_{k_{n}}\right)=0
$$

From (1), (3.32), and (3.35), we have

$$
d(z, T z)=0
$$

Thus $z$ is a fixed point of $T$.

To prove the unique fixed point of $T$, let $z=T z$ and $w=T w$.

Then, by hypothesis, we obtain

$$
\begin{aligned}
& p(w, z)=p(T w, T z) \leq \varphi(\max \{p(w, z), p(w, w), p(z, z), p(z, w)\}), \\
& p(z, w)=p(T z, T w) \leq \varphi(\max \{p(w, z), p(w, w), p(z, z), p(z, w)\}), \\
& p(z, z)=p(T z, T z) \leq \varphi(\max \{p(w, z), p(w, w), p(z, z), p(z, w)\}), \\
& p(w, w)=p(T w, T w) \leq \varphi(\max \{p(w, z), p(w, w), p(z, z), p(z, w)\}) .
\end{aligned}
$$

By (3.36) and the hypothesis

$$
\max \{p(w, z), p(w, w), p(z, z), p(z, w)\}=0
$$

From Lemma 2.3 and (3.37), we have

$$
w=z .
$$

From Theorem 3.5, we have the following corollary. 
Corollary 3.6 Let $(X, d)$ be a complete metric space with a $u$-distance $p$ on $X$. Let $T: X \rightarrow$ $X$ be a mapping that satisfies the following conditions:

(1) $p(T x, T y) \leq k(\max [p(x, y), p(x, T x), p(y, T y), p(x, T y), p(y, T x)$,

$$
p(y, x), p(T x, x), p(T y, y), p(T y, x), p(T x, y)])
$$

for all $x, y \in X$ and for some $k \in(0,1)$;

(2) for each $x \in X$ with $\lim _{n \rightarrow \infty} T^{n} x=c_{x} \in X$, there exists $y \in X$, such that $\lim _{n \rightarrow \infty} T^{n} y=T c_{x}$.

Then $T$ has a unique fixed point $z$ in $X$ and $p(z, z)=0$.

Proof Let $\varphi: R_{+} \rightarrow R_{+}$be defined by

$$
\varphi(t)=k t, \quad 0<k<1
$$

Then, by (3.39), all the conditions of Theorem 3.5 are satisfied.

Thus $T$ has a unique fixed point $z$ in $X$ and $p(z, z)=0$.

Lemma 3.7 Let $(X, d)$ be a complete metric space with a $u$-distance $p$ on $X$ and let $T: X \rightarrow$ $X$ be a mapping satisfying (3.38) and

$$
\inf \{p(x, y)+p(x, T x): x \in X\}>0
$$

for every $y \in X$ with $y \neq T y$.

Then, for each $x \in X$ with $\lim _{n \rightarrow \infty} T^{n} x=c_{x} \in X$, there exists $y \in X$ such that $\lim _{n \rightarrow \infty} T^{n} y=$ $T c_{x}$.

Proof Suppose that there exists some $x \in X$ with $\lim _{n \rightarrow \infty} T^{n} x=c_{x} \in X$ such that

$$
\lim _{n \rightarrow \infty} T^{n} y \neq T c_{x} \quad \text { for all } y \in X .
$$

From (3.41) we get

$$
\lim _{n \rightarrow \infty} T^{n} x=c_{x} \in X \quad \text { and } \quad \lim _{n \rightarrow \infty} T^{n}(T x)=\lim _{n \rightarrow \infty} T^{n+1} x \neq T c_{x} .
$$

Then, by (3.42), the same method as in Theorem 3.5 and simple calculations, we have

$$
c_{x} \neq T c_{x}, \quad \lim _{n \rightarrow \infty} p\left(T^{n} x, c_{x}\right)=0 \quad \text { and } \quad \lim _{n \rightarrow \infty} p\left(T^{n} x, T^{n+1} x\right)=0 .
$$

On account of (3.43) and the hypotheses of Lemma 3.7, we obtain

$$
\begin{aligned}
0 & <\inf \left\{p\left(x, c_{x}\right)+p(x, T x): x \in X\right\} \\
& \leq \inf \left\{p\left(T^{n} x, c_{x}\right)+p\left(T^{n} x, T^{n+1} x\right): n \in N\right\}=0 .
\end{aligned}
$$

This is a contradiction. 
From Corollary 3.6 and Lemma 3.7 we have the following corollary.

Corollary 3.8 ([15]) Let $(X, d)$ be a complete metric space with a $u$-distance $p$ on $X$. Let $T: X \rightarrow X$ be a mapping satisfying (3.38) and (3.40). Then $T$ has a unique fixed point $z$ in $X$ and $p(z, z)=0$.

Proof Since all the conditions of Corollary 3.8 satisfy all the conditions of Corollary 3.6, we obtain result of Corollary 3.8.

In the next example we shall show that all the conditions of Theorem 3.5 are satisfied, but condition (3.38) in Corollary 3.6 and condition (3.40) in Lemma 3.7 are not satisfied.

Example 3.9 Let $k \in(0,1)$ and let $X=[0,1]$ be closed interval with the usual metric, and $p: X \times X \rightarrow R_{+}, T: X \rightarrow X$ and $\varphi: R_{+} \rightarrow R_{+}$be mappings defined as follows:

$$
\begin{aligned}
& p(x, y)=\left(\frac{1-k}{1+k}\right) x, \\
& T x=\left(\frac{1+k}{2}\right) x, \\
& \varphi(t)= \begin{cases}\left(\frac{1+k}{2}\right) t, & 0 \leq t \leq \frac{1-k}{1+k}, \\
\frac{t}{1+t}, & \frac{1-k}{1+k}<t .\end{cases}
\end{aligned}
$$

Define $\theta: X \times X \times R_{+} \times R_{+} \rightarrow R_{+}$by

$$
\theta(x, y, s, t)=s
$$

for all $x, y \in X$ and $s, t \in R_{+}$.

Then, by (3.44) (3.47) and simple calculations, we know that $p$ is a $u$-distance on $X$ and $\varphi$ satisfies (ii) and (iii) in Lemma 3.3. We now show that $\varphi$ satisfies (iv) in Lemma 3.3 .

On account of (3.46), if $0 \leq t \leq \frac{1-k}{1+k}$, then $\varphi^{n}(t)=\left(\frac{1+k}{2}\right)^{n} t$ for all $n \in N$ and so (iv) holds for all $t \in\left[0, \frac{1-k}{1+k}\right]$.

If $t>\frac{1-k}{1+k}$, then there exists $M \in N$ such that

$$
\varphi^{M}(t) \leq \frac{1-k}{1+k}
$$

Suppose that $\varphi^{n}(t)>\frac{1-k}{1+k}$ for all $n \in N$ and $t \in\left(\frac{1-k}{1+k}, \infty\right)$.

Then, by (3.46), $\frac{1-k}{1+k}<\varphi^{n}(t)=\frac{t}{1+n t}$ for all $n \in N$ and $t \in\left(\frac{1-k}{1+k}, \infty\right)$. Thus $0<\frac{1-k}{1+k} \leq$ $\lim _{n \rightarrow \infty} \varphi^{n}(t)=\lim _{n \rightarrow \infty} \frac{t}{1+n t}=0$, a contradiction.

Hence (3.48) holds.

By virtue of (3.46) and (3.48), we get

$$
\varphi^{n}(t)=\varphi^{n-M}\left(\varphi^{M}(t)\right)=\left(\frac{1+k}{2}\right)^{n-M} \cdot \varphi^{M}(t)
$$


for all $n \in N$ with $n>M$. Thus $\varphi$ satisfies (iv) in Lemma 3.3 for $t \in\left(\frac{1-k}{1+k}, \infty\right)$. Therefore (iv) in Lemma 3.3 holds. Using (3.44) (3.46), we have

$$
\begin{aligned}
& \varphi(\max [p(x, y), p(x, T x), p(y, T y), p(x, T y), p(y, T x), \\
& \quad p(y, x), p(T x, x), p(T y, y), p(T y, x), p(T x, y)]) \\
& =\varphi\left(\max \left[\left(\frac{1-k}{1+k}\right) x,\left(\frac{1-k}{1+k}\right) y\right]\right), \\
& p(T x, T y)=\left(\frac{1-k}{1+k}\right) T x=\left(\frac{1-k}{1+k}\right)\left(\frac{1+k}{2}\right) x=\left(\frac{1-k}{2}\right) x \text { and } \\
& \varphi\left(\left(\frac{1-k}{1+k}\right) x\right)=\left(\frac{1+k}{2}\right)\left(\frac{1-k}{1+k}\right) x=\left(\frac{1-k}{2}\right) x
\end{aligned}
$$

for all $x, y \in X$.

By (3.49), (c1) of Definition 3.4 is satisfied.

Due to (3.45), since $\lim _{n \rightarrow \infty} T^{n} x=\lim _{n \rightarrow \infty}\left(\frac{1+k}{2}\right)^{n} x=0$ for each $x \in X$, there exists $y=\frac{x}{2} \in X$ such that $\lim _{n \rightarrow \infty} T^{n} y=\lim _{n \rightarrow \infty}\left(\frac{1+k}{2}\right)^{n} \cdot \frac{x}{2}=0=T 0$.

This implies (c2) of Definition 3.4.

Therefore all the conditions of Theorem 3.5 are satisfied.

By means of (3.44) and (3.45), there exist $a=1 \in X$ and $b=0 \in X$ such that

$$
\begin{aligned}
& k \cdot \max \{p(a, b), p(a, T a), p(b, T b), p(a, T b), p(b, T a), \\
&p(b, a), p(T a, a), p(T b, b), p(T b, a), p(T a, b)\} \\
&= k \cdot\left(\frac{1-k}{1+k}\right) \text { and } \\
& p(T a, T b)=\left(\frac{1-k}{1+k}\right) T a=\left(\frac{1-k}{1+k}\right)\left(\frac{1+k}{2}\right)=\left(\frac{1-k}{2}\right) \text { and } \\
& \frac{1-k}{2}>k\left(\frac{1-k}{1+k}\right) \text { for } k \in(0,1) .
\end{aligned}
$$

On account of (3.50), (3.38) in Corollary 3.6 is not satisfied.

In terms of (3.44) and (3.45) we obtain

$$
\begin{aligned}
0 & \leq \inf \{p(x, y)+p(x, T x): x \in X\} \\
& \leq \inf \left\{p\left(T^{n} x, y\right)+p\left(T^{n} x, T^{n+1} x\right): n \in N\right\} \\
& =\inf \left\{\left(\frac{1-k}{1+k}\right) T^{n} x+\left(\frac{1-k}{1+k}\right) T^{n} x: n \in N\right\} \\
& =\inf \left\{2\left(\frac{1-k}{1+k}\right) \cdot\left(\frac{1+k}{2}\right)^{n} x: n \in N\right\}=0
\end{aligned}
$$

for all $y \in X$ with $y \neq T y$. This means that (3.40) in Lemma 3.7 is not satisfied.

Remark 3.10 It follows from Lemma 3.7 and Example 3.9 that Theorem 3.5 is a proper extension of Corollary 3.6 and Corollary 3.8, the results of Ćirić [5], Kannan [12] and Ume [15]. 
The following theorem is a generalization of Suzuki's fixed point theorem [18].

Theorem 3.11 Let $(X, d)$ be a complete metric space with a $u$-distance $p$ on $X$. Let $\varphi: R_{+} \rightarrow$ $R_{+}$be a mapping satisfying conditions (ii) (iv) of Lemma 3.3 .

Let $T: X \rightarrow X$ be a mapping that satisfies the following conditions:

(i) $p\left(T x, T^{2} x\right) \leq \varphi(p(x, T x))$ for all $x \in X$;

(ii) If $\lim _{n \rightarrow \infty} \sup \left\{p\left(x_{n}, x_{m}\right): m>n\right\}=0, \lim _{n \rightarrow \infty} p\left(x_{n}, T x_{n}\right)=0$ and

$$
\lim _{n \rightarrow \infty} p\left(x_{n}, y\right)=0 \text {, then } T y=y \text {. }
$$

Then there exists $z \in X$ such that $T z=z$ and $p(z, z)=0$.

Proof By (3.51), the same methods in Theorem 3.5 and simple calculations, we deduce that

$$
\begin{aligned}
& \lim _{n \rightarrow \infty} \sup \left\{p\left(T^{n} x, T^{m} x\right): m>n\right\}=0, \quad \lim _{n \rightarrow \infty} T^{n} x=z, \\
& \lim _{n \rightarrow \infty} p\left(T^{n} x, z\right)=0 \quad \text { and } \quad \lim _{n \rightarrow \infty} p\left(T^{n} x, T^{n+1} x\right)=0 .
\end{aligned}
$$

By means of (3.52) and hypotheses (i), (ii), we obtain

$$
T z=z \quad \text { and } \quad p(z, z)=0 \quad \text { and } \quad z \text { is a unique fixed point of } T .
$$

Corollary 3.12 ([18]) Let $(X, d)$ be a complete metric space with a $\tau$-distance $p$ on $X$. Let $T: X \rightarrow X$ be a mapping satisfying (ii) of Theorem 3.11 and

$$
p\left(T x, T^{2} x\right) \leq k p(x, T x)
$$

for all $x \in X$ and some $k \in(0,1)$.

Then $T$ has a unique fixed point $z$ in $X$ and $p(z, z)=0$.

Proof Let $\varphi: R_{+} \rightarrow R_{+}$be defined by

$$
\varphi(t)=k t, \quad 0<k<1 .
$$

Since $p$ is a $\tau$-distance, $p$ is a $u$-distance. Thus all the conditions of Theorem 3.11 are satisfied.

Therefore $T$ has a unique fixed point $z$ in $X$ and $p(z, z)=0$.

\section{Existence of a solution for an integral equation}

In what follows, we assume that $X=C([0,1])$ is the set of all continuous functions defined on $[0,1]$ and $\varphi: R_{+} \rightarrow R_{+}$satisfy conditions (ii), (iii), and (iv) of Lemma 3.3. Let $d, p: X \times$ $X \rightarrow R_{+}$and $\theta: X \times X \times R_{+} \times R_{+} \rightarrow R_{+}$be mappings defined as follows:

$$
d(x, y)=\sup _{t \in[0,1]}|x(t)-y(t)|, \quad p(x, y)=\sup _{t \in[0,1]}|x(t)|
$$


and

$$
\theta(x, y, s, t)=s
$$

for all $x, y \in X$ and $s, t \in R_{+}$. Then clearly $(X, d)$ is a complete metric space and $p$ is a $u$-distance on $X$. Now we prove the existence theorem for a solution of the following integral equation by using Theorem 3.5:

$$
x(t)=r(x, t)+\int_{0}^{1} G(t, s) f(s, x(s)) d s,
$$

where $x \in X, r: X \times R \rightarrow R, G:[0,1] \times[0,1] \rightarrow R$ and $f:[0,1] \times R \rightarrow R$ are given mappings.

Theorem 4.1 Suppose that the following hypotheses hold:

( $\left.\mathrm{I}_{1}\right) \quad r: X \times R \rightarrow R$ is a continuous mapping such that

$$
|r(x, t)| \leq \frac{1}{2} \varphi(|x(t)|) \quad \text { for all } x \in X \text { and } t \in R
$$

$\left(\mathrm{I}_{2}\right) \quad G:[0,1] \times[0,1] \rightarrow R$ is a continuous mapping such that

$$
|G(t, s)| \leq \frac{1}{2} \quad \text { for all } t, s \in[0,1]
$$

( $\left.\mathrm{I}_{3}\right) f:[0,1] \times R \rightarrow R$ is a continuous mapping such that

$$
|f(s, x(s))| \leq \varphi(|x(s)|) \quad \text { for all } x \in X \text { and } s \in[0,1] \text {. }
$$

$\left(\mathrm{I}_{4}\right)$ For each $x \in X$ with $\lim _{n \rightarrow \infty} T^{n} x=c_{x} \in X$, there exists $y \in X$ such that $\lim _{n \rightarrow \infty} T^{n} y=$ $T c_{x}$.

Then the integral equation (4.1) has a solution $x \in X$.

Proof Let $T: X \rightarrow X$ be a mapping defined by

$$
(T x)(t)=r(x, t)+\int_{0}^{1} G(t, s) f(s, x(s)) d s
$$

for all $x \in X$ and $t \in[0,1]$. By conditions $\left(\mathrm{I}_{1}\right),\left(\mathrm{I}_{2}\right)$, and $\left(\mathrm{I}_{3}\right)$, we have

$$
\begin{aligned}
|(T x)(t)| & =\left|r(x, t)+\int_{0}^{1} G(t, s) f(s, x(s)) d s\right| \\
& \leq|r(x, t)|+\left|\int_{0}^{1} G(t, s) f(s, x(s)) d s\right| \\
& \leq|r(x, t)|+\int_{0}^{1}|G(t, s)||f(s, x(s))| d s \\
& \leq|r(x, t)|+\frac{1}{2} \int_{0}^{1}|f(s, x(s))| d s \\
& \leq|r(x, t)|+\frac{1}{2} \int_{0}^{1} \varphi(|x(s)|) d s
\end{aligned}
$$




$$
\begin{aligned}
& \leq \frac{1}{2} \varphi(|x(t)|)+\frac{1}{2} \int_{0}^{1} \varphi\left(\sup _{t \in[0,1]}|x(t)|\right) d s \\
& \leq \frac{1}{2} \varphi(|x(t)|)+\frac{1}{2} \varphi\left(\sup _{t \in[0,1]}|x(t)|\right)
\end{aligned}
$$

for all $x \in X$ and $t \in[0,1]$. Then

$$
\begin{aligned}
p(T x, T y)= & \sup _{t \in[0,1]}|(T x)(t)| \leq \sup _{t \in[0,1]}\left\{\frac{1}{2} \varphi(|x(t)|)+\frac{1}{2} \varphi\left(\sup _{t \in[0,1]}|x(t)|\right)\right\} \\
\leq & \frac{1}{2} \varphi\left(\sup _{t \in[0,1]}|x(t)|\right)+\frac{1}{2} \varphi\left(\sup _{t \in[0,1]}|x(t)|\right) \\
= & \varphi\left(\sup _{t \in[0,1]}|x(t)|\right) \\
\leq & \left.\varphi\left(\max _{\{} \sup _{t \in[0,1]}(|x(t)|), \sup _{t \in[0,1]}|y(t)|, \sup _{t \in[0,1]}|(T x)(t)|, \sup _{t \in[0,1]}|(T y)(t)|\right\}\right) \\
= & \varphi(\max \{p(x, y), p(x, T x), p(y, T y), p(x, T y), p(y, T x), \\
& p(y, x), p(T x, x), p(T y, y), p(T y, x), p(T x, y)\})
\end{aligned}
$$

for all $x, y \in X$.

Thus all of the hypotheses of Theorem 3.5 are satisfied. Hence the mapping $T$ has a fixed point that is a solution in $X=C([0,1])$ of the integral equation (4.1).

\section{Competing interests}

The author declares that he has no competing interests.

\section{Author's contributions}

The author completed the paper himself. The author read and approved the final manuscript.

\section{Acknowledgement}

This research was supported by Basic Science Research Program through the National Research Foundation of Korea (NRF) funded by the Ministry of Science, ICT \& Future Planning (2013R1A1A2057665).

\section{Received: 23 February 2015 Accepted: 26 June 2015 Published online: 16 July 2015}

\section{References}

1. Agarwal, RP, Hussain, N, Taoudi, M-A: Fixed point theorems in ordered Banach spaces and applications to nonlinear integral equations. Abstr. Appl. Anal. 2012, Article ID 245872 (2012)

2. Aydi, H, Samet, B, Vetro, C: Coupled fixed point results in cone metric spaces for $\tilde{w}$-compatible mappings. Fixed Point Theory Appl. 2011, Article ID 27 (2011)

3. Banach, S: Sur les opérations dans les ensembles abstraits et leur application aux équations intègrales. Fundam. Math. 3, 133-181 (1922)

4. Caristi, J: Fixed point theorems for mappings satisfying inwardness conditions. Trans. Am. Math. Soc. 215, 241-251 (1976)

5. Cirić, LB: A generalization of Banach's contraction principle. Proc. Am. Math. Soc. 45, 267-273 (1974)

6. Ćirić, LB: Solving the Banach fixed point principle for nonlinear contractions in probabilistic metric spaces. Nonlinear Anal. 72, 2009-2018 (2010)

7. Ćirić, LB, Abbas, M, Saadati, R, Hussain, N: Common fixed points of almost generalized contractive mappings in ordered metric spaces. Appl. Math. Comput. 217, 5784-5789 (2011)

8. Cvetković, AS, Stanić, MP, Dimitrijević, S, Simić, S: Common fixed point theorems for four mappings on cone metric type space. Fixed Point Theory Appl. 2011, Article ID 589725 (2011)

9. Hussain, N, Dorić, D, Kadelburg, Z, Radenović, S: Suzuki-type fixed point results in metric type spaces. Fixed Point Theory Appl. 2012, Article ID 126 (2012)

10. Jungck, G, Rhoades, BE: Fixed point theorems for occasionally weakly compatible mappings. Fixed Point Theory 7 , 287-296 (2006)

11. Jungck, G, Radenović, S, Radojević, S, Rakočević, V: Common fixed point theorems for weakly compatible pairs on cone metric spaces. Fixed Point Theory Appl. 2009, Article ID 643840 (2009)

12. Kannan, R: Some results on fixed points II. Am. Math. Mon. 76, 405-408 (1969)

13. Parvaneh, $V$, Roshan, JR, Radenović, S: Existence of tripled coincidence point in ordered $b$-metric spaces and application to a system of integral equations. Fixed Point Theory Appl. 2013, Article ID 130 (2013) 
14. Ume, JS: Extensions of minimization theorems and fixed point theorems on a quasimetric space. Fixed Point Theory Appl. 2008, Article ID 230101 (2008)

15. Ume, JS: Existence theorems for generalized distance on complete metric spaces. Fixed Point Theory Appl. 2010, Article ID 397150 (2010)

16. Ume, JS: Fixed point theorems for nonlinear contractions in Menger spaces. Abstr. Appl. Anal. 2011, Article ID 143959 (2011)

17. Ume, JS: Common fixed point theorems for nonlinear contractions in a Menger space. Fixed Point Theory Appl. 2013, Article ID 166 (2013)

18. Suzuki, T: Generalized distance and existence theorems in complete metric spaces. J. Math. Anal. Appl. 253, 440-458 (2001)

Submit your manuscript to a SpringerOpen ${ }^{\circ}$ journal and benefit from:

- Convenient online submission

- Rigorous peer review

- Immediate publication on acceptance

- Open access: articles freely available online

- High visibility within the field

- Retaining the copyright to your article

Submit your next manuscript at $\boldsymbol{~ s p r i n g e r o p e n . c o m ~}$ 